\title{
Criança diabética do tipo 1 e o convívio familiar: repercussões no manejo da doença
}

\author{
Diabetic child of type 1 and family life: repercussions in the \\ management of the disease
}

Thais Schmidt Vitali Hermes ${ }^{\mathbf{1}}$, Cláudia Silveira Vieraㄹ, Rosa Maria Rodrigues $\mathbf{3}$, Beatriz Rosana Gonçalves de Oliveira Toso ${ }^{4}$, Luciana Mara Monti Fonseca ${ }^{5}$

DOI: 10.1590/0103-1104201811911

1 Universidade Estadual do Oeste do Paraná (Unioeste) - Cascavel (PR), Brasil Orcid: https://orcid. org/0000-0003-02045045

thaisschmidtvitali@gmail. com

2 Universidade Estadual do Oeste do Paraná (Unioeste) - Cascavel (PR), Brasil

Orcid: https://orcid. org/0000-0002-09004660

clausviera@gmail.com

3 Universidade Estadual do Oeste do Paraná (Unioeste) - Cascavel (PR), Brasil Orcid: https://orcid. org/0000-0002-7047037X

rmrodri09@gmail.com

4 Universidade Estadual do Oeste do Paraná

(Unioeste) - Cascavel (PR), Brasil

Orcid: https://orcid org/0000-0001-7366077X

Ib.toso@gmail.com

5 Universidade de São Paulo (USP) - São Paulo (SP), Brasil

Orcid: https://orcid.

org/0000-0002-5831-

8789

lumonti@eerp.usp.br
RESUMO A pesquisa objetivou escrever a repercussão do convívio familiar da criança diabética no manejo da doença. Trata-se de um estudo qualitativo descritivo, tipo estudo de caso, com criança diabética em seguimento ambulatorial de um hospital universitário, por meio de grupo focal. Análise de dados por análise de conteúdo do tipo temática. Observou-se que Adriana (nome fictício), 11 anos, não adere às orientações e tratamentos propostos pela equipe de saúde, resultando em inadequado manejo do diabetes e altos índices glicêmicos, decorrente da relação desarmoniosa com a família e da carência de gestão dos serviços de saúde. Condições crônicas de saúde interferem no cotidiano familiar e dificultam o tratamento, especialmente de crianças. A Atenção Primária à Saúde deve utilizar ferramentas como a gestão de caso e o projeto terapêutico singular para que, em conjunto com a família e com a criança, possa obter melhor adesão ao tratamento.

PALAVRAS-CHAVE Diabetes Mellitus. Criança. Relatos de caso. Assistência integral à saúde.

\begin{abstract}
The research aimed to write the repercussion of the family life of the diabetic child in the management of the disease. This is a descriptive qualitative study, type case study with a diabetic child followed in an outpatient follow-up at a university hospital, through a focus group. Analysis of data by content analysis of thematic type. Adriana (fictitious name), 11 years old, does not adhere to the guidelines and treatments proposed by the health team, resulting in inadequate management of diabetes and high glycemic indexes. Disharmonious relationship with the family and the lack of health services management could contributed with this situation. Chronic health conditions influence the family daily life and make treatment difficult, especially for children. Primary Health Care should use tools such as case management and the singular therapeutic project so that, together with family and child, it can obtain better adherence to the treatment.
\end{abstract}

KEYWORDS Diabetes Mellitus. Child. Case reports. Comprehensive health care. 


\section{Introdução}

O Diabetes Mellitus Tipo 1 (DM1) é a segunda doença crônica mais prevalente na infância', havendo cerca de 500 mil crianças e adolescentes com DM1 no mundo ${ }^{2}$. Com evolução lenta e progressiva, requer tratamento intensivo de alto custo, sendo considerado um problema emergente na saúde da criança, exigindo atenção especializada e acompanhamento em longo prazo nas unidades de Atenção Primária a Saúde (APS).

Não obstante, o tratamento isolado é insuficiente, fazendo-se necessários adequada adesão e mudanças no cotidiano de vida das crianças e das suas famílias. Demanda, então, tomada de decisões distintas, relativas a comportamentos de saúde, como gestão da nutrição, prática de atividade física, bem como cuidados específicos como monitorização da glicemia capilar e aplicação das múltiplas injeções de insulina ${ }^{\mathbf{3} 4}$.

A família é o principal suporte no processo de adoecimento infantil, pois a experiência do sofrimento é compartilhada e tende a conformar-se em apoio mútuo 5 . Entretanto, quanto mais nova for, mais conflitos são gerados entre a criança e seus familiares, visto que ela não compreende bem sua condição. Dessa forma, as determinações de cuidados como restrição alimentar, glicosimetria e insulinoterapia podem gerar raiva e tristeza nessas crianças, haja vista que se sentem punidas por algo que tenham feito, assim como angústia nos familiares, que ainda não sabem lidar com a situação ${ }^{6}$.

O suporte às dimensões positivas do funcionamento familiar são considerados preditores significativos para maior adesão ao tratamento, melhor controle glicêmico e adequado manejo da doença ${ }^{7}$. No entanto, nas distintas conformações familiares, cada grupo reagirá conforme seus valores, cultura e compreensões sobre a doença. Diante do conflito familiar preexistente, que pode agravar-se com a vivência do DM1 da criança, pode haver fragilização do suporte dos pais/cuidadores e de responsabilidade perante o manejo da doença, influenciando negativamente na adesão ao tratamento ${ }^{8}$. A relação familiar saudável proporciona segurança à criança e facilita sua adaptação à doença; assim, ela obtém maior colaboração nas atividades de cuidado exigidas.

Manejar eficazmente o DM1 na infância implica envolvimento contínuo das crianças, da família e dos profissionais de saúde na busca do equilíbrio biológico, psíquico e social delas por meio da ótica do cuidado integral. As redes de apoio familiar e social às crianças diabéticas conformam estratégias que favorecem seu bem-estar e o gerenciamento do cuidado, elementos fundamentais para o planejamento da atenção às condições crônicas ${ }^{5}$.

Considerando esses aspectos, a rede de apoio necessária para sucesso terapêutico e a necessidade de aproximação com o contexto de vida dessas famílias, surgiu o seguinte questionamento: como o convívio familiar da criança diabética do tipo 1 pode repercutir no manejo da doença?

Este estudo, portanto, objetiva descrever a repercussão do convívio familiar da criança diabética no manejo da doença.

\section{Metodologia}

Estudo qualitativo, tipo estudo de caso singular, com criança e familiar captados durante grupo focal de pesquisa, que originou a dissertação de mestrado 'Educação em saúde para crianças diabéticas por meio de cartilha educativa e abordagem lúdica'.

Estudo de caso qualitativo é uma abordagem utilizada para compreender e explorar fenômenos de pessoas ou grupos particulares em seu contexto natural, gerando dados por meio de múltiplas fontes e fornecendo análises de representações holísticas9,10.

O rigor metodológico do estudo de caso obteve-se seguindo-se seis estágios: definição do caso (pergunta de pesquisa embasada na literatura); seleção do caso, identificando-o na modalidade intrínseca; coleta de dados triangulação de dados (entrevistas, grupos 
focais e observações), aumentando a validade interna do estudo; interpretação dos dados, revisão repetida, organização e codificação dos dados e, relato do estudo de caso, permitindo a compreensão dos processos seguidos e como as conclusões foram alcançadas ${ }^{10}$.

Nos encontros do grupo focal da pesquisa primária, que descreveu a repercussão da educação em saúde direcionada a crianças com DM1 em relação ao manejo da doença, emergiu o caso de um binômio criança-familiar que demonstrou relação conflituosa, associada ao manejo inadequado da doença pela criança. Surgiu, então, a proposta de descrever esse caso, o qual se constitui o próprio objeto da pesquisa, em que o pesquisador procura compreendê-lo em profundidade e singularidade ${ }^{10}$.

A coleta de dados ocorreu em encontros dialógicos pautados em atividades lúdicas e entrevista conduzida por questões disparadoras. Dados foram gravados em áudio, transcritos na íntegra e importados para o programa Nvivo. Documentaram-se em diário de campo as reflexões dos pesquisadores e observações em campo, constituindo-se ferramenta importante para interpretação do estudo de caso.

Os dados foram submetidos à análise de conteúdo tipo temática. As entrevistas, após transcrição, passaram por leitura flutuante com organização das unidades de registro e de contexto, sendo estas reagrupadas em categorias após leitura exaustiva do material, com auxílio do software Nvivo. A seguir, buscou-se desvendar o conteúdo subjacente, ideologias e tendências dos fenômenos em análise; por fim, a interpretação articulou os dados e os referenciais teóricos da pesquisa. A categorização ocorreu mediante o agrupamento das unidades de registro e contexto sob um título geral de acordo com suas características comuns ${ }^{11}$. Esse processo analítico originou duas categorias: Repercussão da condição crônica no contexto familiar; Dificuldade da criança ante o DM1.

Garantiu-se o anonimato da criança e do familiar mediante nomes fictícios. O estudo atendeu aos preceitos éticos de pesquisa envolvendo seres humanos, aprovado por Comitê de Ética e Pesquisa sob o parecer n ${ }^{\circ} 1.836 .139$ da Universidade Estadual do Oeste do Paraná.

\section{Resultados e discussão}

O caso em análise refere-se à Adriana, 11 anos, portadora de DM1, que reside com a avó Maria, 46 anos - e com seu companheiro desde os 3 anos de idade. Filha de mãe adolescente (14 anos) usuária de substâncias tóxicas e de pai presidiário. Como a mãe não tinha condições de criá-la, principalmente após a descoberta da doença, a avó requereu sua guarda legal. A renda mensal da família é entre um e dois salários mínimos. Adriana faz uso de insulina com esquema de Glargina 24UI/dia + Lantus ação rápida de cinco a mais vezes ao dia, não realiza rodízio dos locais de aplicação. A aplicação de insulina e o hemoglicoteste (HGT) são as atividades mais difíceis para ela devido à dor. Admite não seguir a dieta e consume doces diariamente, mesmo sabendo dos riscos da má alimentação, afirmando que pode ficar internada. Não permanece por longos períodos em jejum e pratica atividade física recreativa, mas não reconhece os benefícios das atividades para o controle glicêmico. Identifica situações de hipo e hiperglicemias e relata como age em cada situação. Apresenta glicemia de jejum de $438 \mathrm{mg} / \mathrm{dL}$, hemoglobina glicada de $12,1 \%$ e glicemia média semanal capilar de $337,54 \mathrm{mg} / \mathrm{dL}$. Resultados muito elevados quando comparados às metas glicêmicas para crianças diabéticas, segundo a Sociedade Brasileira de Diabetes $(\mathrm{SBD})^{2}$, considerados de alto risco para desenvolvimento de complicações crônicas.

Com o diagnóstico do DM1, a família e a criança passam a viver a condição crônica de saúde, implicando ameaça para a rotina familiar perante as mudanças nos comportamentos e hábitos de vida. Entende-se a condição crônica no contexto da determinação social do processo saúde-doença, tomando-se o referencial de Dahlgren e Whitehead ${ }^{12}$, que demonstra a forma de atuação dos determinantes sociais da saúde sobre as iniquidades 
nos grupos sociais, distribuindo em camadas, conforme níveis de abrangência ${ }^{12}$. Examinando o caso específico da condição crônica do diabetes em criança, percebe-se a idade como condicionante relacionado com o indivíduo. Relativo ao estilo de vida, tem-se a alimentação inadequada e a ausência de exercícios físicos regulares. Nas condições socioeconômicas, culturais e ambientais, encontrou-se como determinantes a formação e estrutura familiar, a baixa renda, o transporte, a moradia, a alimentação e o acesso limitado aos serviços de saúde; aspectos que contribuem para um funcionamento familiar alterado ${ }^{13}$.

Para que a equipe de saúde preste assistência adequada e aumente a sobrevida dessas crianças, a compreensão da repercussão do diabetes no contexto familiar, considerando a determinação social do processo saúde-doença, é necessária; assim como a avaliação do funcionamento familiar diante da condição de saúde do filho, pois as alterações na vida familiar têm sido ligadas ao pobre funcionamento emocional e comportamental, o que influencia na adesão aos tratamentos ${ }^{13}$.

\section{Repercussão da condição crônica no contexto familiar}

Alguns genitores não estão preparados para assumir a responsabilidade de realizar todos os cuidados que a condição crônica demanda. Consequentemente, as tarefas são assumidas por outro membro familiar. Ocasionalmente, essa transferência de compromissos gera mudança inesperada no cotidiano do novo responsável, que pode interpretar tal fato como interrupção dos seus projetos de vida.

No meu caso pedi a guarda dela, porque a minha filha saía, não parava muito em casa [...] com isso, parou toda a minha vida, mudou tudo, eu tinha prestado vestibular, tinha meus sonhos, parei de trabalhar, de estudar. Congelei meus sonhos, estou quase descongelando, porque penso que ano que vem já quero fazer uma faculdade, porque senão a vida dela segue e eu vou ficando pra trás [...]. (Maria, avó da Adriana).

Maria não percebe a condição crônica e os cuidados que assumiu em relação à neta como oportunidade de contribuir para a adesão ao tratamento da DM1, mas considera como um período que não obteve realização pessoal e que agora que a criança está maior, tem chance de viver novamente. $\mathrm{O}$ surgimento da condição crônica na infância ocasiona transformações no cotidiano das famílias, resultando em processo de desestruturação e modificação dos papéis: um dos membros limita o tempo para realização pessoal e acaba abandonando o emprego diante das exigências de cuidados impostos ${ }^{14-16}$.

A aceitação da condição crônica está relacionada com a singularidade de cada membro familiar, alguns aceitam facilmente enquanto outros podem nunca chegar a essa premissa. Quando aceito, repercute positivamente no cotidiano, resultando em apoio à criança, melhor comunicação e responsabilidades compartilhadas. Contrariamente, provoca momentos conflituosos que interferem na rotina e nos cuidados com a doença. Torna-se imprescindível preparar os profissionais de saúde para perceberem o funcionamento familiar após o diagnóstico da DM1 e ofertar escuta qualificada para identificarem conjuntamente as melhores estratégias de enfrentamento da doença, promovendo orientações de maneira clara e no momento adequado ${ }^{17}$.

No estudo deste caso, apreendeu-se que a avó expressa esperança de maior reconhecimento por parte da neta pelos cuidados providos. Contudo, desconsidera as necessidades da criança; a idade; a imaturidade e a compreensão do processo de adoecimento.

Ela acaba com a vida de quem está ao redor também [...]. Não pode contar [com ninguém], não pode contar com pai, com mãe, só tem a mim, se eu virar as costas, ela dançou! Eu disse que viro, pode me cobrar se chegar a acontecer algum problema por causa do diabetes, eu 'pincho' em um órgão do Estado e desapareço. Não sou obrigada a cuidar, estou fazendo tudo agora e ela não 
colabora. Se nós saímos daqui, na primeira banca ela olha e diz 'me compra uma coxinha', aquilo chega a doer. Tenho vontade de matar, porque $o$ que adiantou todo esse tempo aqui [atividade educativa], se ela vai rir da minha cara depois. (Maria, avó da Adriana).

Sentimentos conflitantes da avó em relação à neta emergem, havendo uma responsabilização sobre a criança pela sua situação de vida, ou seja, a obrigatoriedade do cuidado, ao mesmo tempo que imputa ameaças de abandono; isso verbalizado para os pesquisadores em frente à criança, responsabilizando-a por seu autocuidado. Apesar da guarda legal, Maria não demonstra responsabilidade afetiva com Adriana, parece não se sentir responsável pelos cuidados com a doença, tendo dificuldade em lidar como a solicitação de alimentos que não devem fazer parte da dieta da menina. Acredita que essas são atitudes de desafio da neta, e não comportamentos comuns em crianças, que devem ser regidos pelos adultos.

Esse tipo de demonstração diante dos pesquisadores gerou inquietação e tentativas do grupo, formado por enfermeiros - e, portanto, insuficiente para a atenção psicológica necessária -, de buscar apoio interdisciplinar, propiciando acompanhamento psicológico para o binômio do caso estudado. Contudo, sem sucesso, devido ao descrédito da família em relação a esse seguimento, por tentativas frustradas anteriores ao vivenciado na época da pesquisa.

No cotidiano do viver com DM1, as rotinas são direcionadas aos cuidados com a condição crônica, e outras preocupações ficam em segundo plano. Raiva, revolta, frustração, inconformismo e negação, também apresentados por Maria, são mais comuns na identificação do diagnóstico, mas também podem perpassar todo curso da doença' ${ }^{\mathbf{1 8}}$.

As atitudes da criança diante dos hábitos alimentares são inaceitáveis na visão da avó, o que reflete no relacionamento entre elas. Os frequentes estados de hiperglicemia apresentados provocam glicosúria e diurese osmótica, consequentemente, desidratação.
A necessidade de compensação desta leva à modificação dos hábitos, trazendo a enurese noturna, poliúria e polidpsia ${ }^{13}$, resultando em reação em cadeia que prejudica a qualidade de vida e enfraquece a relação familiar, fato que parece passar despercebido pela avó.

Maria acredita saber o suficiente sobre a condição crônica e que não necessita de orientações, dificultando mais a interação entre ela, Adriana e os serviços de saúde. Em seu ponto de vista, a situação que a família vivencia é decorrente das atitudes da neta e que ajuda não é necessária, a solução seria a mudança nas atitudes da criança.

A gente já sabe, pesquiso muito, assisto as palestras. O médico senta, fica uma hora com ela. Psicólogo que eu já a levei, ficou seis meses em tratamento [...]. Então, vim por desencargo de consciência mesmo, mas sabia que não ia adiantar nada, mas vim para dizer que fiz tudo que estava no meu alcance, mas volto a dizer, não adiantou nada. (Maria, avó da Adriana).

Ante o exposto, a equipe de pesquisa, por meio da atuação interdisciplinar, buscou propiciar à avó momentos de reflexão sobre suas crenças de cuidado e responsabilização da criança, embora sem obter resultados favoráveis. Maria expressa a necessidade de resultados imediatos em relação a todas as tentativas de acompanhamento que já realizou, não há percepção de que a condição de saúde em que a neta e toda família está envolvida é crônica, com necessidades em longo prazo.

Essa urgência resulta tanto da falta de orientação desde o momento do diagnóstico quanto da assistência interdisciplinar e singular. $\mathrm{O}$ tratamento da doença, as consultas e acompanhamentos frequentes, bem como a rotina intensa de cuidados, são os principais geradores de conflitos entre familiares e portadores do DM1. Geralmente, as famílias respondem bem a essa nova contingência, mas são observadas atitudes não cooperativas perante o processo de adoecimento em famílias cujas estruturas já estavam desgastadas, situação 
dificilmente contornada ${ }^{\mathbf{1 5}, \mathbf{1 6}}$. Como observado no depoimento da Maria, ao acreditar que os acompanhamentos não "adiantam nada" e que leva a neta por "desencargo de consciência", o que remete que atendimentos fragmentados não são eficazes ${ }^{19}$.

A atuação da APS no território dessa família é essencial para formação de vínculo e do acolhimento para estabelecer confiança no serviço e equipe e nas propostas estabelecidas de cuidado. Na fala da avó, identificam-se a valorização da rede de apoio disponível no território e a fragmentação na disponibilidade dos serviços, requerendo longos deslocamentos, bem como a ineficácia do tratamento, justificada quando menciona não querer ir à consulta:

Não fui ainda [na psicóloga], porque fazem 40 dias que eu operei e só meu marido trabalhando, só temos um carro, não tem como ele parar de trabalhar para ir lá levar. De ônibus, aquele terminal [municipal] me faz mal. Tem tudo isso, aí não tem como. Se saísse lá no bairro, porque sei que tem órgãos lá perto, agora esse aqui é complicado pegar três ônibus. Vou esperar mais um pouco [...] E assim, se for com a mesma que a gente já foi uma vez nem quero, porque não vi resultado. (Maria, avó da Adriana).

Com o relato de Maria, evidenciam-se os fatores condicionantes sobre o processo saúde-doença, mencionados anteriormente, e identifica-se que o cuidador precisa de apoio, sente-se cansado e limitado no manejo da doença, sem a cooperação da criança, mas, sobretudo, com limitado acesso aos serviços de saúde. A avó não consegue sozinha compreender que a criança não tem consciência da dimensão do problema crônico e que também sofre com a doença. Assim, percebe-se a necessidade de orientação e de acompanhamento para a avó, diante do complexo cotidiano que vivencia.

Vai ficar mais dois anos comigo, se eu aguentar, porque estou seriamente decidida em entregar ela para o conselho tutelar, porque não estou mais aguentando [...]. Já estou a um passo de ir parar dentro de um hospício. Não estou vivendo, um inseto tem vida própria e eu não tenho, sou pior que um inseto, porque vivo a vida dela [...]. Se conseguir esperar até os 18 anos, que daí eu já cumpri a minha parte, quero ir embora para bem longe, não quero nem saber o que está acontecendo. (Maria, avó da Adriana).

Nota-se, uma vez mais, a desresponsabilização pelo cuidado, demonstrando fraco vínculo familiar, em que cobranças se sobrepõem à compreensão da condição vivida pela neta. Consequentemente, Adriana reage de forma negativa e agressiva, com reflexo no manejo da doença, uma vez que tem frequentes estados de hiperglicemia, burla o controle alimentar e aplicações de insulina.

Essa família aparenta viver naquilo que estudo ${ }^{20(500)}$ denominou como o fenômeno da "fragilização das funções parentais", o qual denuncia a existência de pais que não conseguiram se apropriar das mudanças ocorridas na atualidade, de modo equilibrado. Assim, não conseguem

[...] proporcionar uma educação não rígida, que dê maior espaço para a participação da criança na família, promovendo formas de relações mais compreensivas e próximas da mesma, ao mesmo tempo em que reconheçam que a criança em idade precoce precisa ser orientada, em termos de limites, e respeitada dentro de suas possibilidades e capacidades características.

As perturbações familiares podem resultar em sequelas emocionais severas, tanto para a criança quanto para o cuidador. O DM1 e a família influenciam-se mutuamente, a condição altera a rotina e o relacionamento familiar, o que repercute diretamente no controle da doença. A avaliação clínica do nível intelectual do grupo familiar, estilo de tratamento do estresse e dados psicopatológicos devem ser consideradas para bom manejo da doença ${ }^{14}$.

As dificuldades do contexto familiar em que estão inseridas Adriana e Maria implicam 
a adesão ao tratamento e o manejo da doença, contribuindo para elevados índices glicêmicos e influenciando em todo contexto de vida dessa criança. Dessa forma, pode afetar seu crescimento, desenvolvimento, rendimento escolar, comportamental e resultar em incapacidades físicas e mentais futuras, assim como acelerar o aparecimento das complicações tardias do DM1.

Todos esses fatores podem ser resultantes do tratamento prescritivo, com foco no biológico, desconsiderando fatores psicológicos e sociais que envolvem toda a problemática da doença e da família. A total transferência de saberes e responsabilidades para criança e família, sem relação mútua, de confiança e cooperação, ecoa em dificuldades ao manejar a doença e seguir orientações ${ }^{\mathbf{1 7}}$.

\section{Dificuldade da criança ante o DM1}

A criança precisa ser protagonista de sua própria saúde, e os profissionais e as famílias devem atuar de maneira conjunta, empoderando a prática do autocuidado. Maria afirma que auxiliou no controle da alimentação da Adriana por muito tempo, mas agora acredita que esse cuidado não é mais necessário, pois a criança tem idade para realizar essa tarefa sozinha.

Fiz isso [controlar alimentar] muito tempo, mas ela não está mais com dois, têm 11 anos, tá na hora de saber este posso, este não posso, porque não é mais bebê, é uma adolescente. Não posso criar uma pessoa egoísta dentro de casa que tudo gira ao redor dela, vai chegar na casa de um parente ou amigo e obrigar todo mundo comer igual a ela, porque ficou com vontade? [...] tem que começar a se conscientizar, eu respeito os itens dela, ela tem que começar a respeitar os meus também. (Maria, avó da Adriana).

A transferência de cuidados para a criança parece ser uma forma de a avó minimizar sua responsabilidade com a neta. Não há compreensão de que todos os membros da família precisam se corresponsabilizar e apoiar a criança para que ela se adapte às condições impostas pelo DM1, principalmente aquelas relacionadas com a alimentação.

O entendimento sobre o controle de si inicia-se por volta dos 4 anos de idade, evoluindo no decorrer do desenvolvimento infantil. Conforme suas experiências, a criança pode adquirir comportamentos autônomos entre os 8 e 11 anos. Conhecendo esse aspecto do desenvolvimento, essa independência deve ser estimulada nas crianças portadoras de DM1 com apoio dos familiares e da equipe de saúde, adaptando as necessidades à singularidade de cada criança, promovendo segurança nas situações de ausência do responsável, como na escola e nos momentos de lazer ${ }^{18}$.

A existência de sintomas dolorosos relacionados com alguns cuidados que a criança passa a assumir pode alterar o seu funcionamento físico e mental, provocar aborrecimentos e contribuir para que ela desconsidere esses importantes cuidados. Esses fatores potencializam o estresse entre os membros familiares e podem dificultar a transferência de responsabilidades ${ }^{15}$.

Maria sugere opções de tratamento para controlar o que ela e a neta não estão conseguindo sozinhas, como a fome excessiva da Adriana, em busca de soluções para que a criança não precise realizar tantas injeções.

Acho que deveria ter um remédio para controlar o cérebro, para mandar essa informação [que comeu e está satisfeita] [...] e também se os laboratórios ao invés de injetar, fazer pastilha [de insulina] que era bem mais fácil para eles [diabéticos]. (Maria, avó da Adriana).

Resultados similares apontaram que ao serem questionadas o que mudariam no tratamento dos filhos, mães relataram que retirariam ou diminuiriam a quantidade de medicamentos injetáveis ${ }^{18}$. Na vivência com o DM1, faz-se nítido o sentimento ambíguo entre as crianças em seguir o tratamento correto, mesmo este sendo doloroso e com muitas restrições, ou sofrer as consequências das complicações. 
Além disso, Maria afirma que, por vezes, ela mesma realiza a aplicação da insulina diária, pois Adriana aplica uma quantidade maior de unidades da insulina para poder consumir mais doces:

Quando tenho doce em casa, eu aplico, porque daí tem 'neguinho' [referindo-se a Adriana] que por querer comer, vai lá e dá uma dose maior para poder comer o doce. (Maria, avó da Adriana).

Esse é um fator preocupante, pois, para consumir alimentos que desejam, mas não podem, as crianças fazem uso excessivo de insulina, situação também evidenciada no estudo de Leal15. Essa atitude também pode ser justificada pela necessidade de aceitação da criança ou adolescente no meio social ${ }^{\mathbf{1 4}}$.

A discordância entre avó e neta vai além dos cuidados diários do DM1. Nas demais atividades cotidianas, também Adriana apresenta dificuldade em seguir as condutas idealizadas pela Maria.

Adriana é um caso à parte mesmo, não sei o que tem que ser feito, eu gostaria de descobrir [...]. Porque é tão preguiçosa, mas tão preguiçosa que meu Deus do céu, para tomar banho mando 50 vezes. Aí me irrito, passo a mão numa vara, daí ela vai, uma menina desse tamanho, e quando tiver do meu tamanho será que eu vou ter que andar com uma vara atrás dela, até o prato dela eu tenho que fazer, para lavar um prato para mim dentro de casa eu preciso ameaçar bater, do contrário, não vai [...]. (Maria, avó da Adriana).

A rotina intensiva para o adequado manejo do DM1 pode fazer com que a criança sinta raiva da doença e do tratamento, acarretando que ela deixe de realizar diversas atividades por estar saturada. A dificuldade da avó em compreender a doença para a criança e em impor-lhe limites necessários geram situações estressoras em seu convívio. A transição da infância para adolescência é uma fase associada a comportamentos impulsivos; e, em portadores de condições crônicas, há maior risco de problemas como autoestima, depressão e ansiedade, com frequência duas vezes maior que em crianças saudáveis ${ }^{\mathbf{1 4 , 1 8}}$.

Adriana demonstrou estar ciente dos cuidados que devem ser realizados para bom manejo da doença e controle glicêmico, contudo, é evidente a negação dela acerca da doença e da necessidade de seguir esses cuidados.

Cegueira, amputação, vai parar internada. (Adriana, 11 anos, em resposta à questão Conhece os riscos de uma má alimentação?).

Ela não tem medo dessa doença, vê pessoa amputada, cega, essa semana nós fizemos uma consulta com o doutor, eu perguntei se tinha alguma complicação em subir a dosagem [da insulina], ele disse assim: 'Adriana, a cada dosagem que eu subo pra você, é como se eu estivesse enfiando uma faquinha no seu rim, no seu coração, você está morrendo aos poucos [...]'... Ela acha que o médico está mentindo, acha que pode acontecer com todo mundo, menos com ela. (Maria, avó da Adriana).

Devido à resistência da Adriana em seguir os cuidados com a doença, indiretamente a avó compartilha suas angústias e medos das complicações do DM1, no entanto, demonstra esses sentimentos de forma agressiva, tornando-se evidente que o binômio está em processo de adoecimento mútuo.

Não quero que isso aconteça [complicações], por isso que trago ela nas palestras, para que se conscientize bem, porque se acontecer, eu jogo na cara de que você sabia, você estava avisada e pagou para ver, então fique sozinha. Posso ficar dormindo dentro de casa, eu não vou [ajudar] e não sinto pena, porque eu fiz a minha parte, se ela não quis fazer a dela. (Maria, avó da Adriana).

Complicações das doenças crônicas na infância geram prejuízo, em longo prazo, no crescimento e desenvolvimento infantil, assim como para sua vida adulta. $\mathrm{O}$ início precoce de desenvolvimento do DM1 aumenta o risco de surgimento 
dessas complicações por estarem diretamente relacionadas com a duração do diabetes e com os frequentes quadros de hiperglicemia ${ }^{21}$. Crianças diabéticas necessitam de internação hospitalar quatro vezes mais que as saudáveis, portanto, além de onerar o serviço de saúde, há aumento do estresse psicológico da criança e da família com as constantes internações ${ }^{22}$.

Diante das possíveis complicações do DM1 em algum momento da vida da criança, a adesão adequada ao tratamento é fundamental. Para que isso ocorra, é preciso que os serviços de saúde disponham de estratégias capazes de deliberarem sob a magnitude desse problema, partindo das necessidades apresentadas pela família e pela criança.

Os desafios para os profissionais de saúde estão em integrar conhecimentos dos pais com seus conhecimentos, envolvendo tecnologias leves, mediante as relações estabelecidas nos encontros com os usuários, e leve-duras, em que os recursos intelectuais subsidiam o agir dos profissionais ${ }^{23}$. Ademais, a implementação de atividades lúdicas para trabalhar a educação em saúde promove aproximação com a criança, aumenta a comunicação e atenua medos e anseios, criando vínculo e confiança, no qual as atividades do DM1 tornam-se mais compreensíveis ${ }^{24}$.

Cada família é única, singular, assim, há necessidade de relação dialógica e empática entre elas e os profissionais de saúde para que se conheça o contexto que os envolve ${ }^{16}$. $\mathrm{O}$ sucesso no manejo dessas condições, portanto, está pautado na transformação do sistema de saúde fragmentado para sistema proativo, integrado, focado na pessoa, família e comunidade, mediante ações planejadas e promovidas por equipe multiprofissional e interdisciplinar. Ações que vão além do atendimento presencial, como a atenção compartilhada a grupo, contínua, por pares e a distância ${ }^{19}$.

Em nenhum momento, Maria citou o apoio dos serviços de saúde, tanto da APS quanto ambulatorial. Observa-se total isolamento do manejo do caso de Adriana, que fica sob a custódia da avó. Não há gestão de caso, a APS parece desconhecer o que se passa no interior da família de Adriana e como isso repercute em seu tratamento. Evidencia-se aqui a fragilidade do serviço de APS no manejo da condição crônica de saúde, nesse caso da DM1 na infância. A conduta desta situação deveria ter o total amparo das equipes da APS, que, por meio da escuta qualificada, levantaria as reais necessidades dessa família e, em conjunto, proporia o manejo do DM1 pela gestão de casos, que são direcionados para essas situações crônicas de saúde muito complexas, como proposto por Mendes ${ }^{25}$ na gestão da clínica.

A gestão do caso objetiva acompanhamento direcionado, trazendo como questão central a singularidade, o que permite a utilização de abordagens terapêuticas baseadas nas diferenças e peculiaridades de cada indivíduo, reconhecendo a dimensão individual e familiar e as relações conflituosas entre cuidadores e ser cuidado, devido à complexidade dos laços familiares, à sobrecarga de trabalho e às exigências do cuidado, aumentando sua qualidade e diminuindo a fragmentação da atenção à saúde ${ }^{19,26}$.

Ocorre, então, a identificação do caso de condição de saúde muito complexa. É desenvolvido processo cooperativo entre o profissional de saúde gestor de caso, a pessoa portadora e sua rede de suporte (família, escola, entre outros), para planejar, monitorar e avaliar opções de cuidados e de coordenação da atenção à saúde, pautadas nas necessidades da pessoa que promovam a atenção qualificada, humanizada, capaz de aumentar a capacidade funcional e de preservar a autonomia individual e familiar, de modo que os sujeitos tenham voz durante o processo de cuidado $\mathbf{2 7 , 2 8}$.

Para o melhor manejo da doença e sucesso terapêutico de Adriana, com objetivo de estimular a adesão ao plano de cuidado, de ajustar as necessidades de saúde da sua família aos serviços disponíveis, de melhorar a comunicação entre a família e os profissionais de saúde, de incrementar a capacidade de autocuidado e de melhorar a qualidade de vida da criança e da relação intrafamiliar, a gestão do caso foi esboçada na figura 1 . 
Figura 1. Gestão de caso

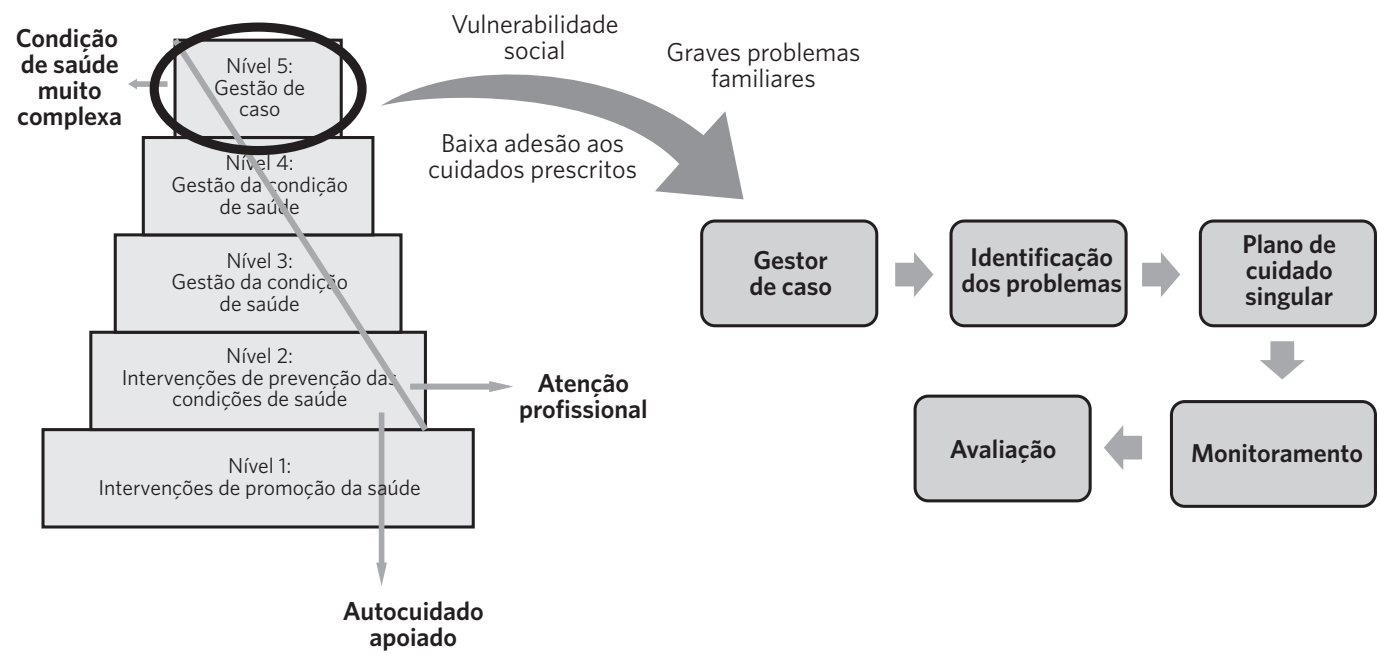

A definição da complexidade do caso da Adriana deu-se com base na vulnerabilidade social; nos graves problemas familiares e na baixa adesão aos cuidados prescritos. A definição do gestor do caso deve considerar a experiência do profissional na gestão de equipes de trabalho; a competência para identificação das necessidades físicas, psicológicas e sociais; a garantia de cuidado humanizado e de qualidade; estando presente, conhecendo a evolução do sujeito e instruindo sobre os cuidados a serem providos.

Para qualificar o atendimento às condições crônicas, portanto, emerge a construção do Projeto Terapêutico Singular, conjunto de propostas de condutas terapêuticas construídas a partir da corresponsabilização da equipe interdisciplinar com a criança e sua rede de suporte social, por meio do diagnóstico, da definição de metas, da divisão de responsabilidades e reavaliação das metas, desenvolvido em diferentes pontos de atenção ${ }^{\mathbf{2 8 , 2 9}}$. A identificação dos problemas é baseada por entrevista com a criança, familiares, amigos, membros da rede de suporte social e profissionais da APS, análise de capacidade de autocuidado, do ambiente familiar e domiciliar. Para elaboração do plano de cuidado singular, algumas perguntas deverão ser respondidas: 0 que necessita ser feito? Como fazer? Quem e quando proverá os serviços? Quando os objetivos serão alcançados?
O monitoramento e a avaliação visam evitar problemas potenciais com adoção de medidas preventivas, proveem contato humanizado com as crianças e as famílias, reduzem eventos adversos, o uso de serviços de urgência e emergência e os custos da atenção e aumentam a autonomia das pessoas e famílias.

Ao considerar os riscos e as vulnerabilidades, pode-se contribuir para o estabelecimento de prioridades, elucidação do plano terapêutico singular e coordenação pela APS das condições crônicas em seu território; de modo a definir a complexidade e os pontos de atenção adequados para manejo do caso, sob a gestão de um coordenador da APS, visando contribuir para melhor lidar com o diabetes na infância, reduzir os riscos de complicações agudas e crônicas e melhorar a qualidade de vida dessas crianças e de suas famílias.

\section{Colaboradores}

Hermes TSV, contribuição substancial para a concepção e o desenho do trabalho, para a análise e interpretação dos dados para o trabalho. Viera CS, contribuição substancial para a elaboração do trabalho, revisão crítica do conteúdo; e participação na aprovação final da versão a ser publicada. Rodrigues RM, 
contribuição substancial para a elaboração do trabalho e revisão crítica do conteúdo. Toso BRGO, revisão crítica do conteúdo e participação na aprovação final da versão a ser publicada. Fonseca LMM, revisão crítica do conteúdo e participação na aprovação final da versão a ser publicada.

\section{Referências}

1. Santos SP, Oliveira LMB. Baixo peso ao nascer e sua relação com obesidade e síndrome metabólica na infância e adolescência. R. Ci. med. Biol [internet]. 2011 [acesso em 2017 nov 2]; 10(3):329-336. Disponível em: http://www.repositorio.ufba.br:8080/ri/bitstream/ ri/5723/1/5898-16360-1-PB\%5B1\%5D.pdf.

2. Diretrizes da Sociedade Brasileira de Diabetes (20152016). Sociedade Brasileira de Diabetes: São Paulo, 2016.

3. Prado SN, Jiménez EG, Lopéz LY, et al. Análisis de conocimientos, hábitos y destrezas en una población diabética infantil: Intervención de Enfermería. Nutr Hosp [internet]. 2014 [acesso em 2017 set 26]; 30(3):585-593. Disponível em: http://scielo.isciii.es/ $\mathrm{pdf} / \mathrm{nh} / \mathrm{v} 30 \mathrm{n} 3 / 16$ originaloriginalsindromemetaboli co04.pdf.

4. Pelicand J, Fournier C, Le Rhun A, et al. Self-care support in paediatric patients with type 1 diabetes: bridging the gap between patient education and health promotion? A review. Health Expect [internet]. 2015 [acesso em 2017 nov 2]; 18(3):303-311. Disponível em: http://onlinelibrary.wiley.com/doi/10.1111/ hex.12041/epdf.
5. Pennafort VPS, Queiroz MVO, Nascimento LC, et al. Rede e apoio social no cuidado familiar da criança com diabetes. Rev. Bras. Enferm. [internet]. 2016 [acesso em 2017 set 2]; 65(5):912-19. Disponível: http://www.scielo.br/pdf/reben/v69n5/0034-7167-reben-69-05-0912.pdf.

6. Cruz DSM, Collet N, Andrade EMC, et al. Vivência de mães de crianças diabéticas. Esc Anna Nery [internet]. 2017 [acesso em 2017 set 25]; 21(1). Disponível em: http://www.scielo.br/pdf/ean/v21n1/14148145-ean-21-01-e20170002.pdf.

7. Mayberry LS, Osborn CY. Family Support, Medication Adherence, and Glycemic Control Among Adults With Type 2 Diabetes. Diabetes Care. 2012; 35:12391245 .

8. Rintala TM, Jaatinen P, Paavilainen E, et al. Interrelation between adult persons with diabetes and their family: a systematic review of the literature. J Fam Nurs. 2013; 19:3-21.

9. Crowe S, Cresswell K, Robertson A, et al. The case study approach. BMC med. res. methodol. 2011; 11(100). 
10. Milles R. Complexity, representation and practice: Case study as method and methodology. Issues in Educational Research. 2015; 25(3):309-18.

11. Barbour R. Grupos focais. Porto Alegre: Artmed; 2009.

12. Rocha PR, David HMSL. Determinação ou Determinantes? Uma discussão com base na Teoria da Produção Social da Saúde. Rev. Esc. Enferm. USP. 2015; 49(1):129-135

13. Herzer M, Godiwala BS, Hommel KA, et al. Family Functioning in the Context of Pediatric Chronic Conditions J Dev Behav Pediatr [internet]. 2010 [acesso em 2018 maio 20]; 1(1):1-14. Disponível: https://www. ncbi.nlm.nih.gov/pmc/articles/PMC2821736/pdf/ nihms-166882.pdf.

14. Lorenzo AB, Yzquierdo GCC, Gort NB, et al. Repercusión y tratamiento de los aspectos psicosociales de la diabetes mellitus tipo 1 en adolescentes. Rev. Cubana Pediatr. [internet]. 2015 [acesso em 2017 out 20]; 87(1). Disponível em: http://scielo.sld.cu/scielo.php?script $=$ sci_arttext\&pid =S0034-75312015000100011.

15. Leal DT, Fialho FA, Dias IMAV, et al. A vivência dos familiares de crianças e adolescentes portadores de diabetes mellitus tipo 1. Rev. eletrônica enferm [internet]. 2012 [acesso em 2016 set 10]; 14(1):189-196. Disponível em: https://www.fen.ufg.br/fen_revista/ v14/nl/pdf/v14nla22.pdf.

16. Nobrega VM, Reichert APS, Silva KL, et al. Imposições e conflitos no cotidiano das famílias de crianças com doença crônica. Esc. Anna Nery Rer. Enferm [internet]. 2012 [acesso em 2017 nov 3]; 16(4):781-788. Disponível: http://www.scielo.br/pdf/ean/vl6n4/20. pdf.

17. Smith J, Cheater F, Beller H. Parents' experiences of living with a child with a long-term condition. Health Expect [internet]. 2013 [acesso em 2017 nov 08]; 18:452-474. Disponível em: https://www.ncbi.nlm. nih.gov/pmc/articles/PMC5060798/pdf/HEX-18452.pdf.
18. Correia Junior PCTC, Pereira SMPD, Almeida VCF, et al. Apreender as repercussões do diabetes mellitus em crianças sob a ótica das mães. Rev. Rene. [acesso em 2017 nov 8]; 60(9):60-69. Disponível em: http:// www.revistarene.ufc.br/revista/index.php/revista/ article/view/1368/pdf.

19. Mendes EV. O cuidado das condições crônicas na atenção primária à saúde: o imperativo da consolidação da estratégia da saúde da família. Brasília, DF: OPAS; 2012.

20. Zanetti SAS, Gomes IC. A "fragilização das funções parentais" na família contemporânea: determinantes e consequências. Temas psicol. 2011 [acesso 2018 maio 12] 19(2): 491-502. Disponível em: http://pepsic.bvsalud.org/scielo.php?script=sci_arttext\&pid=S1413$-389 X 2011000200012 \& \operatorname{lng}=$ pt\&nrm=iso.

21. American Diabetes Association ADA. Standards of medical care in diabetes - 2015. Diabetes Care. 2015; 38(supl1):S1-S93.

22. Fazeli FS, Souverein PC, Van Der Vorst MM, et al. Chronic comorbidities in children with type 1 diabetes: a population-based cohort study. Arch Dis Child. 2015; 100(8):763-768.

23. Teixeira E, Medeiros HP. Tecnologias na literatura de enfermagem: do reconhecimento ao desenvolvimento. In: Nietsche EA, Teixeira E, Medeiros HP. Tecnologias cuidativo-educacionais: uma possibilidade para o empoderamento do(a) enfermeiro(a)? Porto Alegre: Moriá; 2014. p. 57-73.

24. Queiroz MVO, Brito LMMC, Pennafort VPS, et al. Sensibilizando a criança com diabetes para o cuidado de si: Contribuição à prática educativa. Esc. Anna Nery Rev. Enferm [internet]. 2016 abr-jun. [acesso em 2016 out 31]; 20(2):337-343.

25. Mendes EV. As redes de atenção à saúde. Brasília, DF: OPAS; 2011.

26. Cecilio LCO. Apontamentos teórico-conceituais sobre processos avaliativos considerando as múltiplas dimensões da gestão do cuidado em saúde. Comuni- 
cação Saúde e Educação [internet]. 2011 [acesso em 2017 nov 12]; 15(37):589-99. Disponível em: http:// www.scielo.br/pdf/icse/v15n37/a21v15n37.pdf.

27. Powell SK. Case management: a practical guide to success in managed care. Philadelphia: Lippincott Willims \& Williams; 2000.

28. Oliveira RG. Qualificação de gestores do SUS. In: Grabois V. Gestão da atenção à saúde: Gestão do cuidado. Rio de Janeiro: EAD/Ensp; 2009.
29. Brasil. Ministério da Saúde. Secretaria de Atenção à Saúde. Diretrizes para o cuidado das pessoas com doenças crônicas nas redes de atenção à saúde e nas linhas de cuidado prioritárias. Brasília, DF: Ministério da Saúde; 2013.

Recebido em 30/07/2018

Aprovado em 09/11/2018

Conflito de interesses: inexistente

Suporte financeiro: não houve 